\title{
Sand Cement Brick Containing Recycled Concrete Aggregate as Fine-Aggregate Replacement
}

\author{
Faisal Sheikh Khalid ${ }^{1, *}$, Herman Shah Herman ${ }^{1}$, Nurul Bazilah Azmi ${ }^{1}$, and Mohd Irwan \\ Juki $^{1}$ \\ ${ }^{1}$ Jamilus Research Centre, Fakulti Kejuruteraan Awam dan Alam Sekitar, Universiti Tun Hussein \\ Onn Malaysia, 86400, Parit Raja, Batu Pahat, Johor, Malaysia
}

\begin{abstract}
Nowadays, the usage amount of the concrete is increasing drastically. The construction industry is a huge consumer of natural consumer. It is also producing the huge wastage products. The usage of concrete has been charged to be not environmentally friendly due to depletion of reserve natural resources, high energy consumption and disposal issues. The conservation of natural resources and reduction of disposal site by reuse and recycling waste material was interest possibilites. The aim of this study is to determine the physical and mechanical properties of sand cement brick containing recycled concrete aggregate and to determine the optimum mix ratio containing recycled concrete aggregate. An experiment done by comparing the result of control specimen using $100 \%$ natural sand with recycled concrete aggregate replacement specimen by weight for $55 \%, 65 \%$, and $75 \%$. The sample was tested under density, compressive strength, flexural strength and water absorption to study the effect of using recycled concrete aggregate on the physical and mechanical properties of bricks. The result shows that the replacement of natural sand by recycled concrete aggregate at the level of $55 \%$ provide the highest compressive and flexural strength compared to other percentage and control specimen. However, if the replacement higher than $55 \%$, the strength of brick was decreased for compressive and flexural strength, respectively. The relationship of compressive-flexural strength is determined from statistical analysis and the predicted result can be obtained by using equation $\mathrm{f}_{\mathrm{f}, \mathrm{RCA}}=0.5375\left(\mathrm{f}_{\mathrm{c}}\right)^{0.3272}$.
\end{abstract}

\section{Introduction}

Sand cement brick is a kind commonly used in low- and medium-cost housing development and other commercial constructions in Malaysia. Cement and sand brick is easy to make and inexpensive to produce [1]. However, an issue was production cost of sand cement brick using natural sources, especially in developing areas where manufacturers find it difficult to locate adequate sources of natural aggregate supply. Therefore, the price of natural source such sand has increased, which in turn affected pricing of sand cement bricks

*Corresponding author: faisalsh@uthm.edu.my 
[1-2]. Nowadays, many studies focus on the use of waste material in the production of brick concrete.

Therefore, application of recycled materials in the building industry is essential for permanently sustainable development of each county. One possibility is to recycle and reuse waste material concrete. Therefore, recycled concrete aggregate (RCA) as fine aggregate was selected as waste replacement material of sand-aggregate of sand cement brick compared to conventional sand cement brick. Many researchers exhibited that compressive strength of sand cement brick influenced by the physical and mechanical properties of fine RCA. It has been observed from a number of experimental investigations that the compressive strength of concrete using RCA is greatly influenced by the increment in the replacement percentage less than $50 \%$ of RCA using the same water-cement ratio compared to concrete using natural aggregates [3-5]. Other researchers show that recycled fine aggregate presented similar [5] or better performance [5-8] with respect to tensile strength. Concrete with RCA at $25 \%$ to $50 \%$ replacements of sand and aggregates presented sufficient tensile performance compared to normal strength concrete [9-10]. Wojciech et al. [1] claimed that the higher tensile strength of mortar containing fine aggregate is due to the water absorption capacity which is develops a siginificant interfacial bonding between aggregate and matrix. Matias et al. [10] mentioned that the increase in hardened strength is due to the rough surface of recycled fine aggregate which provides better adherence to concrete matrix. Soutsos et al. [11] studied the sand cement brick from waste concrete and bricks to replace coarse and fine aggregates. Southos et al [11] claimed that the brick conatining $60 \%$ replacement of coarse aggregate shows presented significant implications.

Ismail and Yaccob [2] claims that destiny of bricks containing $50 \%$ of recycled fine aggregate content presents slightly increase by $1.7 \%$. The replacement of $50 \%$ and $75 \%$ containing fine aggregates shows significant effects on the compressive strength of the bricks. However, the flexural strength of the brick decreased when the recycled fine aggregate volume exceeds 50\%. Poon et al. [12] declared that the strength of the specimen increased as the percentage of the replacement increased. Not only that, replacement of coarse and fine natural aggregate by recycled aggregates at the level of $25 \%$ and $50 \%$ only had a little effect compressive strength of the bricks and block. Debieb and Kenai [13] claimed the use of crushed brick as coarse and fine aggregates for mortar concrete. The result shows that the mortar concrete shares similar characteristics with natural-aggregate concrete prepare with recycled aggregate. Their finding found that percentage of $25 \%$ and $50 \%$ for coarse and fine aggregates, respectively are percentages presents optimum replacement percentages.

As a conclusion, the potential to manufacture brick containing recycled fine aggregate as replacement sand-aggregate material. This study aim to determine the combination of recycled fine aggregate as replacement material to enhance the strength and durability waste brick compared to conventional sand cement brick. Therefore, the use of recycled fine aggregate material in waste brick production will be promoted a sustainable friendlywaste materials and green building.

\section{Methodology}

The determination of the testing method for optimum mix ratio design of waste brick performance and suitable tools for testing are important to obtain data for analysis purposes. This waste brick was moulded with a mould size $213 \mathrm{~mm}$ in length, $101 \mathrm{~mm}$ in width, and $63 \mathrm{~mm}$ in depth. This study investigated in terms of hardened waste brick to answer the optimum mix ratio of waste RCA. The RCA used in this study were concrete casted in laboratory with strength of $25 \mathrm{MPa}$. These concrete underwent a further process of mechanised crushing and seiving to produce recycled fine aggregate as follow British 
Stadards Instituion [14]. The grain size distributionb of natural sand and recycled fine aggregates as shown in Table 1. Table 2 shows the properties of natural sand and recyled fine aggregate.

Table 1. Sieve analysis of natural and recycled fine aggregate

\begin{tabular}{|c|c|c|}
\hline \multirow{2}{*}{ BS test sieve } & \multicolumn{2}{|c|}{ Percentage passing by weight } \\
\cline { 2 - 3 } & Natural sand & Recycled fine aggregate \\
\hline $2.36 \mathrm{~mm}$ & 93.89 & 79.41 \\
\hline $1.18 \mathrm{~mm}$ & 77.21 & 48.56 \\
\hline 600 & 50.2 & 28.10 \\
\hline 425 & 36.12 & 19.1 \\
\hline 300 & 22.98 & 10.5 \\
\hline 212 & 12.91 & 7.2 \\
\hline 150 & 7.7 & 6.3 \\
\hline
\end{tabular}

Table 2. Properties of natural and recycled fine aggregate

\begin{tabular}{|c|c|c|}
\hline & Natural sand & Recycled fine aggregate \\
\hline Dry surface density $\left(\mathrm{gm}^{3}\right)$ & 2.45 & 2.55 \\
\hline Water absorption (\%) & 11.3 & 4.6 \\
\hline
\end{tabular}

This experiment used recycled fine aggregate as replacement were $55 \%, 65 \%$ and $75 \%$ by weight of natural sand [11]. One bacth of bricks had no recycled fine aggregate content as guide to compare the performance of sand cemnet brick containing recycled fine aggregate. The recycled fine aggregates consist of old cement, mortar and natural stone. Design method of the brick design used by BS 6073 [15]. The sand and cement brick design to exceed $7 \mathrm{~N} / \mathrm{mm}^{2}$ The mix ratio design was $1: 3$. The compressive strength of a material determines its load carrying capacity before failure. British Standards Institution states that the compressive strength of bricks should not be less than $7 \mathrm{~N} / \mathrm{mm}^{2}$. The test was carried out for the sample periods of 7 and 28 days. The sample is placed on compression testing machine. Next, the specimen also tested under flexural strength test. Flexural strength of brick is measure its ability of resists of bending. The sample periods of the specimen that being tested is 28 days.

The water absorption test was conducted to determine the percentage of water absorbed according to the BS 3921:1985, [16] which specify for the testing of bricks. The test also determine the saturation coefficient which is defined as the percentage of pore volume filled in 24 hour of soaking. The test are conducted for $28^{\text {th }}$ days.

\section{Result and discussion}

The experiment was conducted in Heavy Structures Laboratory Universiti Tun Hussein Onn Malaysia. The results and analysis are divided in two parts, namely physical and mechanical properties. All collected data presented in table and graph to assure for a better and clear understanding of the results. 


\subsection{Density test}

The batch of specimens were divided into 4 parts which contains $0 \%, 55 \%, 65 \%$ and $75 \%$ replacement of the recycled fine aggregate. Each part has 6 sample of the specimen for every percentages of 7 days and 28 days. The density of the specimens are calculated by dividing the weight with the volume of the specimens. Fig. 1 shows the average density of sand cement brick with recycled concrete aggregate. From the result, the average of the density for sand brick with recycled fine aggregate are lower compare to control brick. From the result, the most lower can be seen in bricks with $75 \%$ of recycled fine aggregate which reduce the density $4.9 \%$ for 7 days sample and $5.4 \%$ for 28 days sample compared to control bricks.

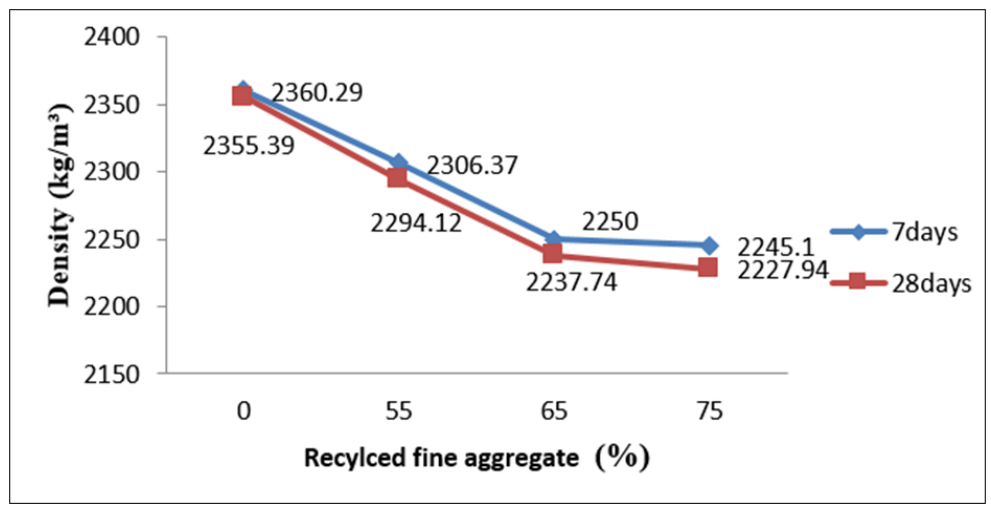

Fig. 1. The average density of sand cement brick with recycled fine aggregate.

\subsection{Compressive strength}

The compressive strength of the specimens determines its load bearing capacity before failure. Fig. 2 shows the average compressive strength of sand cement brick with fine recycled concrete aggregate.

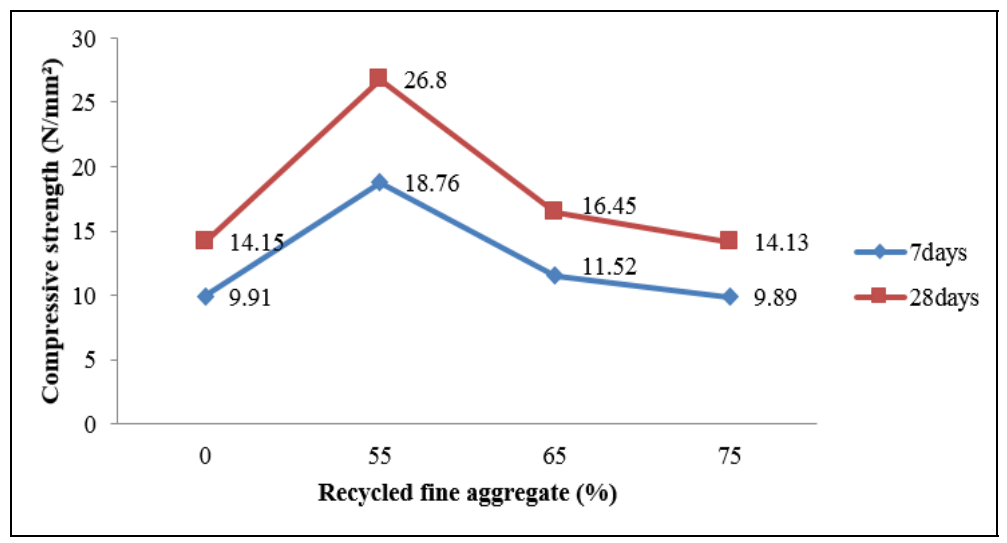

Fig. 2. The average compressive strength of sand cement brick with recycled concrete aggregate.

The specimens period of the sample being tested is 7 days and 28 days with different percentages replacement of recycled fine aggregate. The result shows if the percentage of 
recycled fine aggregate is added over $55 \%$ it will decrease the compressive strength of the brick. From the data collected, it is confirmed that brick with 55\% replacement of recycled fine aggregate has good interlocking well graduation between coarse and finer particles of recycled fine aggregate and more homogeneous[2]. The more angular shape roughfer surface texture of recycled fine aggregate are contribute to a higher compressive. Recycled fine aggregate of 55\% replacement is within a reasonable range to incorporate into sand cement brick. Therefore, 55\% recycled fine aggregate content was selected as the optimum value for natural sand replacment regarding from compressive strength test.

\subsection{Flexural strength}

The specimen period of the sample is 28 days. The flexural strength of the control brick is $1.34 \mathrm{~N} / \mathrm{mm}^{2}$. From the result, the flexural strength increases occur when volume dosage rate recycled fine aggregate increases at $55 \%$ and achieved strength of $1.58 \mathrm{~N} / \mathrm{mm}^{2}$. But it is gradually decreased when it has more than $55 \%$ of volume dosage rate recycled fine aggregate because brick is too porous. It is lead to aggregates are bound not tightly, creating porous and reducing the strength of the brick. Fig. 3 shows the average flexural strength of sand cement brick with recycled fine aggregate. This study presented that the flexural strength of sand cement brick conatining recycled fine aggregate exhibited an increase of $17.9 \%$ ( contains $55 \%$ of recycled fine aggregate), respectively compared to control sand cement brick. Meanwhile, sand cement brick containing $65 \%$ and $75 \%$ of recycled fine aggregate presented decreases of $8.2 \%$ compared to control specimen.

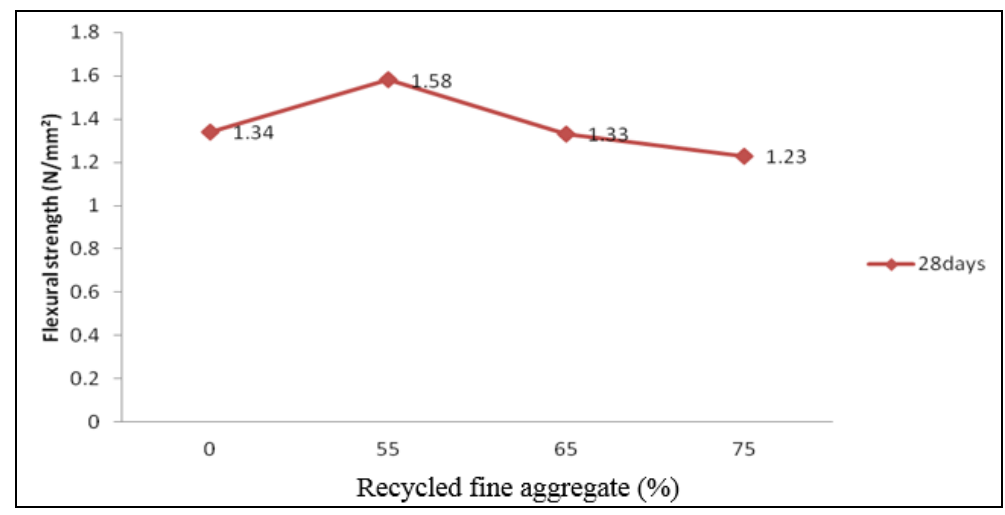

Fig. 3. The average flexural strength of sand cement brick with recycled fine aggregate.

\subsection{Water absorption}

Fig. 4 shows the results on water absorption with time. Water absorption characteristic of sand cement bricks containing recycled fine aggregate increased the water absorption characteristic of brick. Bricks contentaining 55\% of recycled fine aggregate shows similar to the control speciemen. It can be concluede that the density to decrease and the water absorption to increase as the recycled fine aggregate content is increased. The sand cement brick content with 55\% recycled fine aggregate show less permeable compared to control speciemen. The sand cement brick containing with high recycled fine aggregate percentage was more porously than the natural sand. It was due the pore is normally discontinuous in a matrix and being completely enveloped by cement paste in brick. The physical size, shape and random distribution of recycled fine aggregates are more coarser than natural sand 
which is make the packing of mortar matrix becomes less efficient as the recycled aggregate content is increased [2-3].

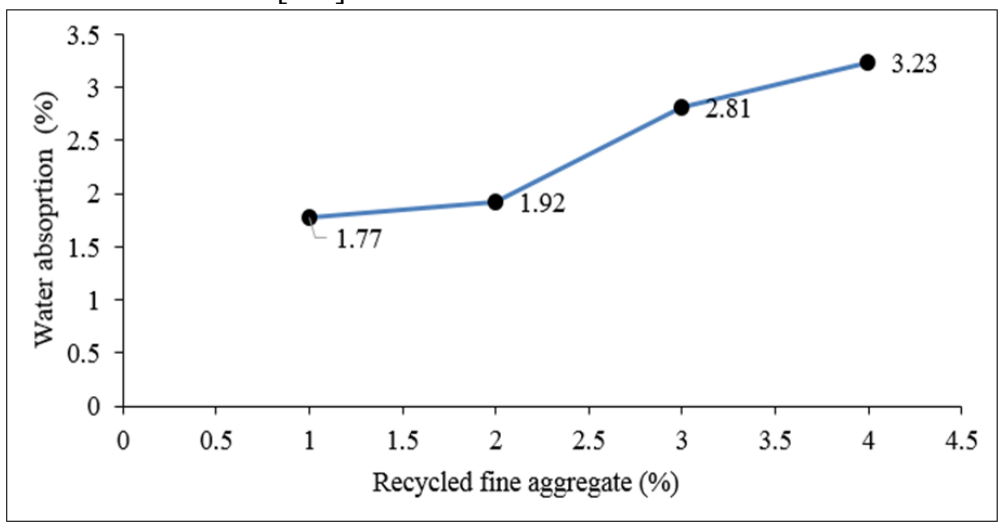

Fig. 4. Water absorption of sand cement brick for 28 days.

\subsection{Compressive-flexural strength relationship}

The compressive-flexural strength relationship are analysed and presented in the table and graph. The comparison of compressive-flexural relationship is determined by using the equation $f_{f, R C A,}=0.5375\left(f_{c}\right)^{0.3272}$. From the calculation, the relationships agreed with experimental result by 1.00 . Table 3 shows Compressive-flexural relationship between experiments and predicted using the equation $f_{f, R C A}=0.5375\left(f_{c}\right)^{0.3272}$.

Table 3. Compressive-flexural relationship between experiments and predicted using the equation $f_{f, R C A,}=0.5375\left(f_{c}\right)^{0.3272}$.

\begin{tabular}{|c|c|c|c|c|}
\hline $\begin{array}{c}\% \\
\text { RCA }\end{array}$ & $f_{c}\left(\mathbf{N} / \mathbf{m m}^{2}\right)$-comp & $f_{f}\left(\mathbf{N} / \mathbf{m m}^{2}\right)$-flexural & Predicted $\boldsymbol{f}_{\boldsymbol{f}} \mathbf{( \mathbf { N } / \mathbf { m m } ^ { 2 } )}$ & $\begin{array}{c}\text { Ratio strength of } \\
\text { predicted with } \\
\text { experimental }\end{array}$ \\
\hline 0 & 14.15 & 1.34 & 1.28 & 0.96 \\
\hline 55 & 26.8 & 1.58 & 1.58 & 1.00 \\
\hline 65 & 16.45 & 1.33 & 1.34 & 1.01 \\
\hline 75 & 14.13 & 1.23 & 1.28 & 1.04 \\
\hline \multicolumn{7}{r|}{ Average } \\
\hline
\end{tabular}

\section{Conclusion}

As the conclusion, the density of sand bricks containing recycled fine aggregate decreases gradually when the percentages of recycled fine aggregate increases. However, the replacement of recycled fine concrete aggregate at the 55\% percentage present significant effects on the compressive strength of the bricks. When the replacements of recycled fine aggregate exceed $55 \%$ it will reduce the compressive strength and flexural strength. The replacment of recycled fine aggregate was increased the water absorption compared to 
control. However, $55 \%$ of replacment presents recycled fine aggregate due to its compressive strength and flexural strength.

This study has been granted by Universiti Tun Hussein Onn Malaysia (UTHM), Malaysia under RAGS Vot. R058.

\section{References}

[1] W. Kubissaa, R. Jaskulskia, A. Kopera, and J. Szpetulski, Properties of concretes with natural aggregate improved by RCA addition, Procedia Engineering, 108, 30-38 (2015)

[2] Ismail and Z. Yaacob, Properties of bricks produced with recycled fine aggregate, Int. J. of Civil, Environmental, Structural, Construction and Architectural Engineering, 4(7), 670-671, (2010)

[3] L.W. Xiao, Y. Fan, and X. Huang, An overview of study on recycled aggregate concrete in China, Construction and Building Materials, 31, 364-83, (2012)

[4] McNeil and T. Kang, Recycled concrete aggregates, Int. J. Concrete Structure Materials, 7(1), 61-9, (2013)

[5] M. Chakradhara Rao, S.K. Bhattacharyya, and S.V. Barai, Influence of field recycled coarse aggregate on properties of concrete, Materials Structure, 44(1), 205-220, (2011)

[6] P. Saravana Kumar and G. Dhinakaran, Effect of admixed recycled aggregate concrete on properties of fresh and hardened concrete, J. Material Civil Engineering, 24(4), 494-498, (2012)

[7] S.K. Faisal, J.M. Irwan, N. Othman, and M.H. Wan Ibrahim, Flexural toughness of ring-shaped waste bottle fiber concrete, The 3rd International Conference on Civil and Environmental Engineering for Sustainability, MATEC Web of Conf., 47(1), 1-6, (2016)

[8] J.M. Irwan, S.K. Faisal, N. Othman, and M.H. Wan Ibrahim, Performance of concrete using light waste PET fibre, Advanced Materials Research, 795, 352-335, (2013)

[9] L. Butler, J.S. West and S.L. Tighe, Effect of recycled concrete coarse aggregate from multiple sources on the hardened properties of concrete with equivalent compressive strength, Construction and Building Materials, 47, 1292-1301, (2013)

[10]D. Matias, J. de Brito, A. Rosa, and D. Pedro, Mechanical properties of concrete produced with recycled coarse aggregates and influence of the use of superplasticizers, Construction and Building Materilas, 44,101-109, (2013)

[11] M.N. Soutsos, S.G. Millard, J.H. Bungey, N. Jones, R.G. Tickell, and J. Gradwell. Using recycled demolition waste in concrete building blocks. Proc. of the Institute of Civil Engineers: Engineering Sustainability, 157(3), 139-148, (2004)

[12]C.S. Poon, S.C. Kou and L. Lam, Use of recycled aggregate in molded concrete bricks and blocks, Construction and Building Materals, 16(5), 281-289, (2002)

[13]F. Debieb, and S. Kenai. The use of coarse and fine crushed bricks as aggregate in concrete, Construction and Building Materials, 22(5), 886-893, (2008)

[14]BS 812, Methods for determination of particle size distribution, Part 103.1, British Standards Institution, London, UK, (1985)

[15]BS 6073, Precast concrete masonry unit, part 1: specification for precast concrete masonry units, part 1, British Standards Institution, London, UK, (1981)

[16]BS 392, specification for clay bricks, Clay Product Standards Committee, British Standard Institution, London, UK, (1985) 